\title{
Carlo Goldoni mal entendido e mal tratado
}

\author{
Sebastiana Fadda
}

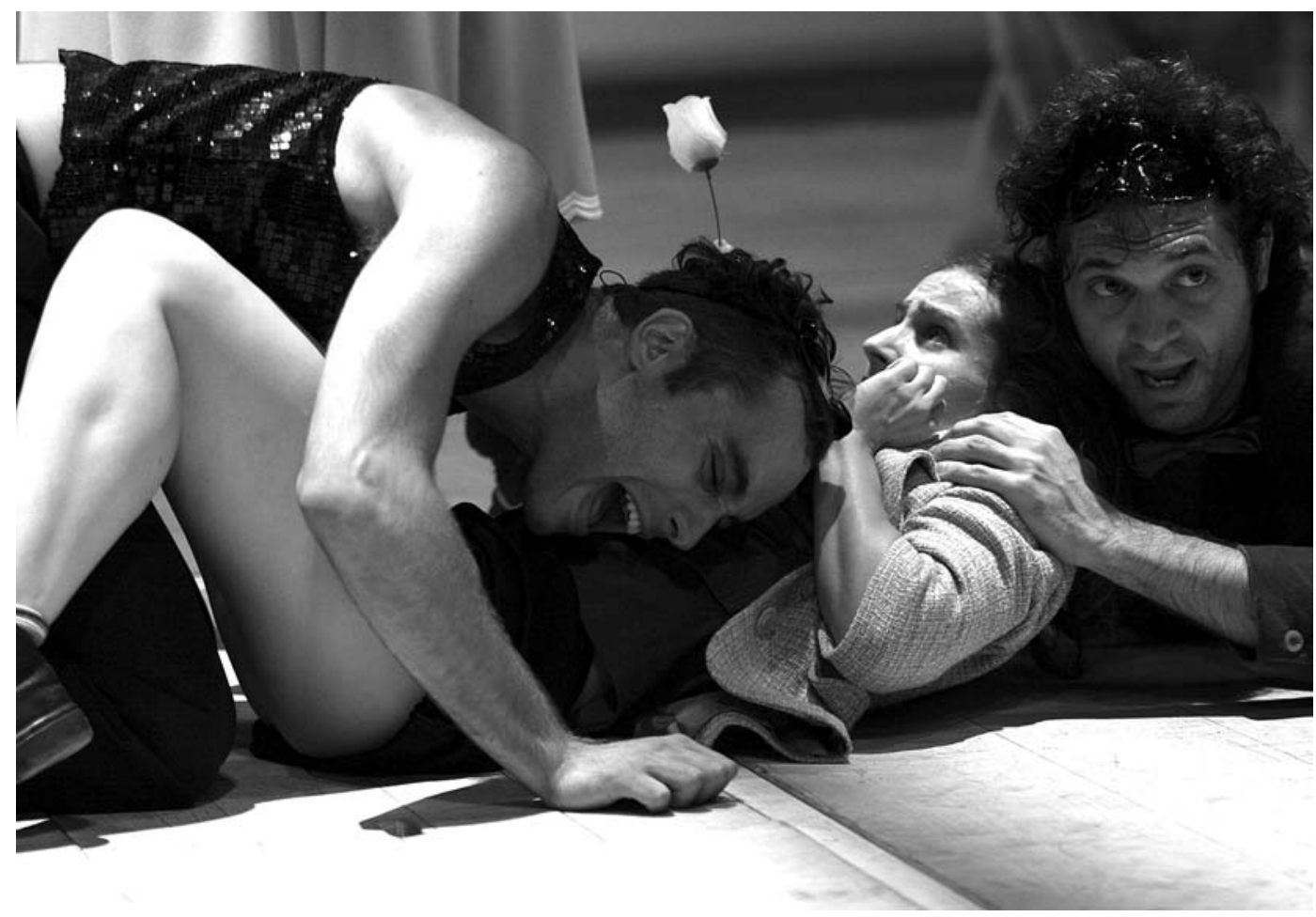

Goldoni Terminus,

de Edoardo Erba, Rui Zink e Tena Stivicic (a partir do canevas de Carlo Goldoni Les inquiétudes de Camille), enc. Toni Cafiero, Dramma Italiano do Teatro Nacional Croato Ivan PI. Zajc de Fiume, Teatro Stabile della Sardegna, Teatro Nacional D. Maria II e Biennale di Venezia, TNDMII, 2007, fot. Drazen Sokcevic.

Titulo: Goldoni Terminus. Texto: Edoardo Erba, Rui Zink e Tena Stivicic. A partir de: Les inquiétudes de Camille canevas en trois actes (10 décembre 1761) de Carlo Goldoni. Encenação: Toni Cafiero. Coordenação: Mani Gotovac. Cenografia: José Manuel Castanheira. Coreografia: Zak Valenta. Música: Darko Jurkovic com o Darko Jurkovic Trio. Iluminação: Maurizio Viani. Intérpretes: Galiano Pahor, Leonora Surian, Mirko Soldano, Rossana Bubbola, Elena Brumini, Rita Cruz, Woody Neri, Massimo Nicolini e Piergiuseppe di Tanno. Co-produção: Dramma Italiano do Teatro Nacional Croato Ivan PI. Zajc de Fiume, Teatro Stabile della Sardegna, Teatro Nacional D. Maria Il e Biennale di Venezia. Local e data de estreia em Portugal: Teatro Nacional D. Maria II (Sala Garrett), Lisboa, 19 de Julho de 2007.

Há quem conteste o lado escatológico de certa forma inerente às comemorações de efemérides, em especial às homenagens post-mortem, pelo facto de por essa via se desenterrarem ciclicamente cadáveres ilustres, caidos no esquecimento em tempos comuns. Mas nesses actos públicos há uma componente ética, que é desejável alimentar e manter viva. Enquanto cidadãos é, pois, francamente consolador saber-se que a memória colectiva não é curta nem branqueia o passado. É por isso de toda a justiça lembrar aquelas personalidades que marcaram a nossa história cívica ou cultural, lançando sementes positivas de esperança e promovendo a expansão do conhecimento no processo evolutivo da humanidade.

As questões que por vezes se levantam dizem respeito ao modo como essa lembrança é manifestada, à sinceridade do impulso que desencadeia os eventos circunstanciais, à honestidade dos contextos em que se inserem ou que acabam por criar.

Estas considerações surgem ligadas a Goldoni Terminus, um dos espectáculos que integraram a segunda edição da Mostra Internacional de Teatro (MITE' 07) organizada pelo Teatro Nacional D. Maria II, uma iniciativa que reclama ser uma importante janela aberta para o mundo, para a criação contemporânea, para as diferentes modalidades de formulação das várias estéticas que co-existem em vários espaços geográficos ou no mesmo espaço de um palco. Trata-se, afinal, da demonstração de uma saudável convivência entre as pluralidades de visões e gostos. Mas esta aspiração à concreta aplicação do regime democrático neste contexto não pode gerar confusões entre os deveres 


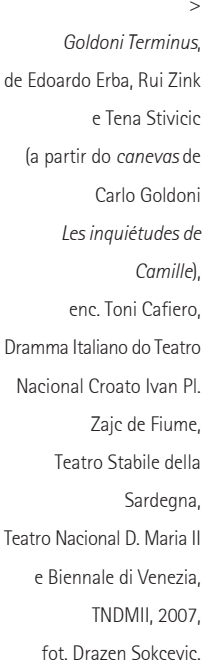

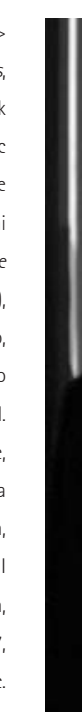
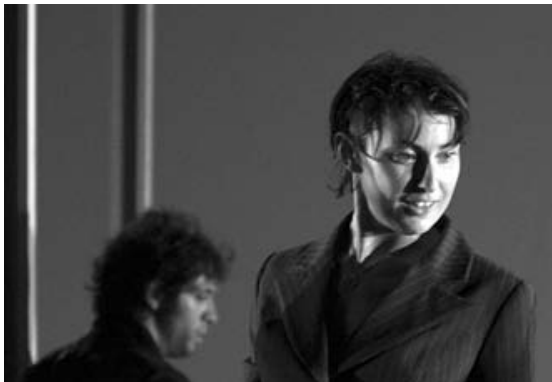

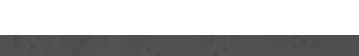

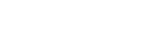

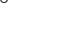




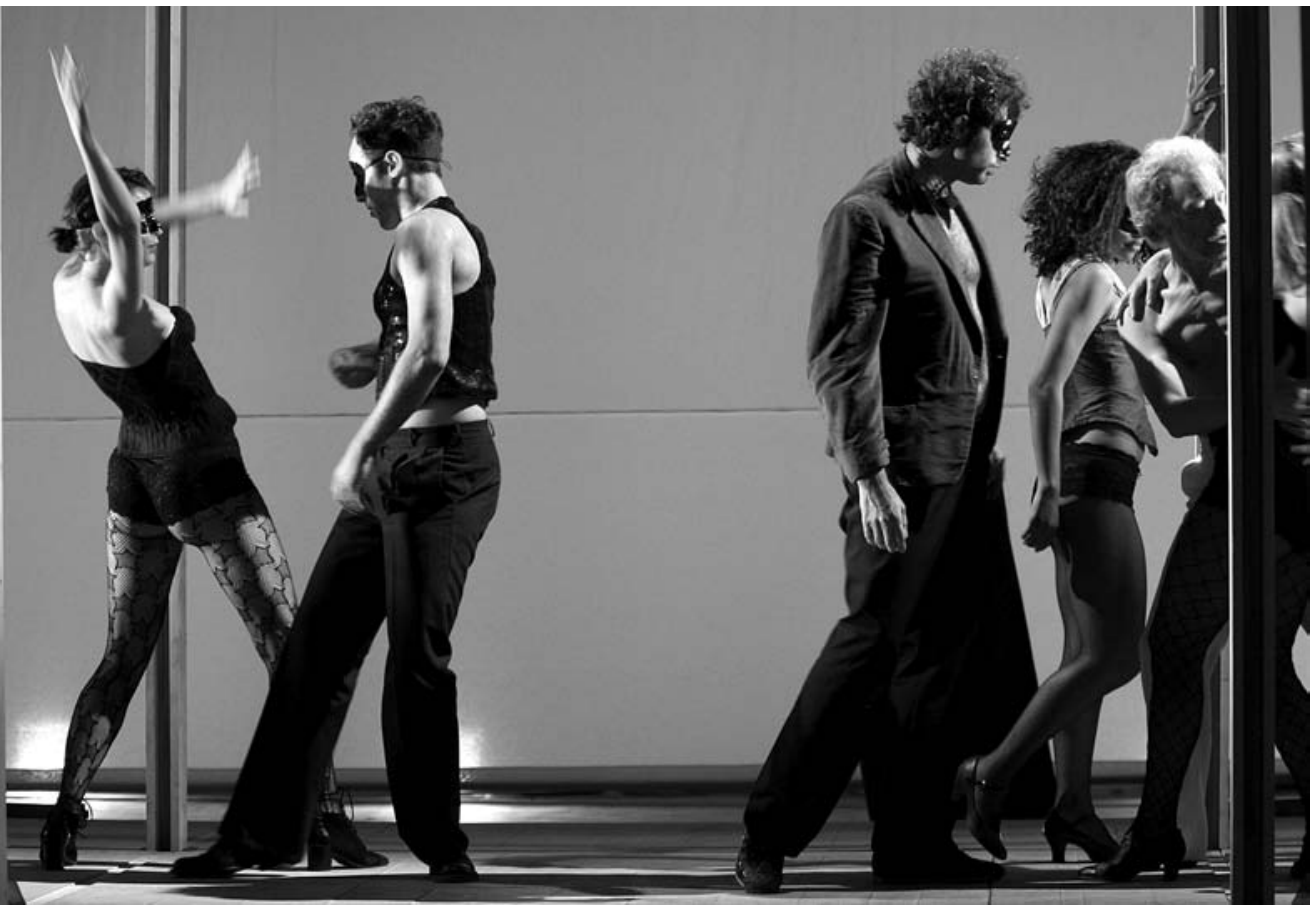

Goldoni Terminus,

de Edoardo Erba, Rui Zink

e Tena Stivicic

(a partir do canevas de

Carlo Goldoni

Les inquiétudes de

Camille),

enc. Toni Cafiero,

Dramma Italiano do Teatro

Nacional Croato Ivan PI.

Zajc de Fiume,

Teatro Stabile della

Sardegna,

Teatro Nacional D. Maria II

e Biennale di Venezia,

TNDMII, 2007,

fot. Drazen Sokcevic.

que não se assistia a uma comédia de costumes à moda de Goldoni, mas que se estava perante uma sua revisitação, sob a forma da comédia musical (em que as canções por vezes eram interpretadas pelos actores, outras vezes vinham de um juke box, numa selecção curiosa e sem critério manifesto). Porém, o conceito de actualização e as relações com a realidade dos nossos dias partiam de bases distorcidas, resultaram de uma leitura mais próxima das vulgares sit-com televisivas de ínfima categoria, que se repercutiam no acima referido enredo, estranhas às indicações goldonianas. Pantaleão, a mulher e o filho geriam um hotel de propriedade de uma suposta multinacional americana. A anunciada e hipotética chegada ao hotel de uma estrelinha do mundo do espectáculo para presenciar a Bienal de Veneza desencadeava acções que desembocavam no nada, porque afinal a vedeta ausente capricharia mudando de ideias à última hora. Uma Camilla coquette, lasciva e ingénua ao mesmo tempo, herdeira da fortuna do falecido patrão, já não lutava pelo amor do seu Arlequim, mas tinha como novo objectivo tornar-se numa diva da música internacional, prestando-se a audições e manipulações por parte do star system que acabaria por a aniquilar.

As ambições do encenador de mostrar a actualidade de Goldoni e as de inserir elementos de crítica à sociedade actual, estavam todavia desajustadas em relação ao produto hibrido a que deu vida. A insistência nos aspectos brejeiros criava um divórcio insanável entre Goldoni Terminus e o Goldoni dramaturgo que serviu de cobaia para um exercício pseudo-artístico e para um evento pseudo-cultural. Por outro lado, o excesso de intermezzi musicais e de bailaricos, que rematavam num fado final, esmoreciam o possivel alcance da denúncia do mundo em que vivemos, revertendo-a no seu contrário, ou seja, numa exaltação do vazio e do espectacular, aptos a satisfazer e divertir destinatários pouco exigentes, mais próximos de consumidores do que de público.

Uma coisa é certa: Goldoni não estava lá. Quem o conhecia ficava na impossibilidade de o encontrar e quem não o conhecesse aumentaria o seu desconhecimento devido à imposição de uma forma superior (ou inferior, dependendo dos pontos de vista) de ignorância. 0 objectivo que tinha dado impulso à co-produção falhou. 0 que sobrou foi uma ideia de teatro de destino discutível por ter sido apresentado em espaços institucionais, e uma visão banalizada e degradada de um certo mundo no qual nem todos se reconhecem, e que é possivel combater com as armas da cultura. Há outros teatros e há mais mundos. Felizmente!

Pela referida parte de tradutora que me coube nesta experiência posso, ainda, testemunhar a minha perplexidade perante o mistério da autoria do texto que assim serviu de base ao espectáculo: quem foi/foram o/os autor/es da peça? Quem coordenou o seu trabalho de maneira a haver uma certa unidade ou pelo menos uma coerência que harmonizasse as diferentes linguagens propostas? Já foram referidas as fragilidades dramatúrgicas e cénicas do espectáculo, já foi mencionada a informação oficial sobre a fonte aparentemente utilizada e sobre os seus reescritores, mas o facto é que da parte assinada por Rui Zink bem pouco sobreviveu. 0 escritor português não assinou um texto mercenário e lesivo dos direitos do seu antecessor, respeitou o espirito e o canovaccio goldonianos, fazendo um trabalho honesto, digno e deontologicamente correcto. Ora, quem alterou, apagou e reescreveu o texto dele?

Como foi possivel transformar as escaramuças amorosas entre Camilla e Arlequim nos anseios de ingresso da jovem criada na feira das vaidades do Olimpo musical?

Não: nem Rui Zink estava lá. Nem nos é dado saber ou formular ilações sobre a responsabilidade dos seus dois colegas quanto à dramaturgia. 0 que se pode inferir é que por certo houve falhas na coordenação que prejudicaram irremediavelmente o espectáculo no seu conjunto, bem como uma falta de comunicação que levou uma leitura de sentido único a dominar sobre outras possiveis e eventuais.

Seria iníquo, porém, falar apenas em aspectos negativos. A cenografia de José Manuel Castanheira, 
minimalista e funcional, teve um bom aproveitamento: muito simples, feita de estruturas de metal que aludiam ao espaço de um palco no palco, sem bambolinas mas com pernas cenografadas que deslizavam com ágeis gestos dos actores mostrando esboços de interiores ou de espaços abertos. Tratou-se de uma solução inteligente, constituindo uma versão modernizada dos antigos cenários em tela pintada. Isso, todavia, foi insuficiente para salvar o espectáculo, pois perante a falta de substância, a forma torna-se ainda mais acessória. A função estética, absolvida também pelo desenho das luzes, não consegue ter autonomia numa arte interdisciplinar como é o teatro, nem bastar por si só para colmatar as lacunas ao nivel dos conteúdos.

Reconheça-se, ainda, que não houve preguiça ou falta de trabalho: os actores bem se esforçaram por serem crediveis e sinceros. Ao longo de quase três horas o seu empenhamento era bem visivel, tal como a tensão final nos seus rostos, no momento de agradecerem os poucos aplausos consolatórios de um público insatisfeito. Tanto esforço mal canalizado era aflitivo para todos. No fim, comungámos a tristeza pela ausência do espírito de Goldoni. Por não ter sido entendido por quem mais teve a possibilidade de o amar, tendo convivido com ele sem o ver, nos meses antecedentes à estreia. Refiro-me ao encenador, pelo seu papel fundamental de deus exmachina da cena. Ou então, ele também: onde esteve?

É evidente que o espectáculo poderia ser analisado sob outras perspectivas. E que para outros analistas a sua qualidade poderia ser considerada excelente, em conformidade com as tendências e as modas de muito teatro pós-moderno que está a ser feito por profissionais respeitados e de prestígio. Ainda, os critérios subjacentes às escolhas do encenador bem podem ter servido outros objectivos, diferentes dos que foram apontados e que até resultam do texto que Margarida Gil dos Reis escreveu para o programa do MITE' 07. Até seria aceitável o intuito de criar um espectáculo polémico, que pusesse em discussão a modernidade de Goldoni de forma provocatória e assumidamente kitsch, mas a questão é que nesse caso devia estar inserido noutro contexto, devia visar outro público e teria sido oportuno escolher outros espaços de apresentação, não convencionais, não institucionais, mas antes privados.

Não sendo assim, é fundamental que os responsáveis pelo projecto se perguntem o que é que aconteceu, o que é que não funcionou no processo de montagem do espectáculo e como se pôde chegar ao desvio das boas intenções iniciais. Chegados a este ponto, não havendo remédio para que já foi feito, o que se pode desejar é que o falhanço seja útil na profilaxia de novos desacertos em futuras operações semelhantes. Que devem ser estimuladas, pois não é a sua validade que está a ser posta em causa, antes pelo contrário, mas é preciso ter sempre bem presentes os pressupostos subjacentes, os objectivos a atingir, bem como o público-alvo e o espaço de apresentação adequado.

Em Lisboa, com o seu fraco entusiasmo, viu-se que o rei andava nu. E não é razão suficiente para amenizar os acontecimentos o facto de o espectáculo ter sido recebido com maior calor por parte do público e da crítica na Bienal de Veneza e na Sardenha. A antropologia demonstra-nos que, nas falsas democracias, não há melhor maneira de controlar o dissentimento do que pela via da assimilação institucional, enquanto a verdadeira transgressão requer autonomia espiritual e financeira.

Esperamos - temos a certeza - de que haverá uma redenção, um resgate da memória goldoniana, numa nova produção que envolverá o Teatro Nacional D. Maria II, o Teatro dos Aloés e o Cendrev, mas quanto a esta experiência internacional, finalmente e em consonância com o pensamento binarista típico da cultura ocidental, poderse-iam formular duas hipóteses: assistimos ao espectáculo errado no teatro certo? Ou ao espectáculo certo no teatro errado? 